\title{
Expedient synthesis of bisabolenol stink bug pheromones via stereodefined cyclohex-2-enones
}

Shyam Shirali, Filadelfo Guzman, Donald C. Weber, and Ashot Khrimian*

USDA-ARS, Invasive Insect Biocontrol and Behavior Laboratory, Beltsville Agricultural

Research Center, Bldg. 007, Rm. 301, 10300 Baltimore Avenue, Beltsville, MD 20705 USA.

* To whom correspondence should be addressed, e-mail: ashot.khrimian@ars.usda.gov. Tel:

(301) 504-6138. Fax: (301) 504-5104.

(C) 2016. This manuscript version is made available under the Elsevier user license 


\section{ABSTRACT}

We recently synthesized all stereoisomers of 1,10-bisaboladien-3-ol and 10,11-epoxy-1bisabolen-3-ol, including three stink bug pheromones, via a rhodium-catalyzed asymmetric addition of trimethylaluminum to diastereomeric mixtures of cyclohex-2-enones. However, yields of trans isomers were low, and scaling reactions using expensive catalysts were cumbersome. Now we describe a new synthesis of bisabolenol stink bug pheromones via $(S)$ and $(R)-4-((R)-6$-methylhept-5-en-2-yl)cyclohex-2-enones prepared by enantioselective Michael additions of methyl vinyl ketone to $(S)$ - and $(R)$-citronellals and lithium hydroxide monohydratecatalyzed stereoselective cyclizations of intermediate ketoaldehydes. Addition of methyllithium to these enones provided cis- and trans-1,10-bisaboladien-3-ols, which were separated by chromatography on silica and further converted to 10,11-epoxy-1-bisabolen-3-ols. Thus, we developed more convenient syntheses of pheromones of the rice stink bug, the harlequin bug, and brown marmorated stink bug.

Keywords: Rice stink bug; Oebalus poecilus; Brown marmorated stink bug; Halyomorpha halys; Harlequin bug; Murgantia histrionic; Pheromones; Michael addition; Robinson annulation 


\section{INTRODUCTION}

There are at least four pentatomid stink bug species that use a bisabolenol entity in their male-secreted pheromone molecules. The rice stalk stink bug, Tibraca limbativentris, sex pheromone was identified as a mixture of two stereoisomers of zingiberenol, or 1,10bisaboladien-3-ol, ${ }^{1}$ without determining their absolute configuration. ${ }^{2}$ The sex pheromone of rice stink bug, Oebalus poecilus, consists of a single isomer of zingiberenol identified as $(3 R, 6 R, 7 S)$ 1,10-bisaboladien-3-ol (1). ${ }^{3,4}$ Interestingly, ginger rhizomes also produce this compound along with $(3 S, 6 R, 7 S)$-1,10-bisaboladien-3-ol (2), as minor components of their sesquiterpene content. ${ }^{5}$ The aggregation pheromone of the harlequin bug, Murgantia histrionica, was identified as 10,11-epoxy-1-bisabolen-3-ol ${ }^{6,7}$ and later revealed to be a 1.4:1 mixture of two stereoisomers, $(3 S, 6 S, 7 R, 10 S)-10,11$-epoxy-1-bisabolen-3-ol (3) and $(3 S, 6 S, 7 R, 10 R)-10,11$-epoxy-1-bisabolen3-ol (4) ${ }^{8}$. Lastly, the brown marmorated stink bug, Halyomorpha halys, has been shown to share compound $\mathbf{3}$ as the main component of its aggregation pheromone, along with $(3 R, 6 S, 7 R, 10 S)$ 10,11-epoxy-1-bisabolen-3-ol (5), produced by the male bug in a 3.5:1 ratio. ${ }^{9}$ The last two stink bug species are important agricultural pests for which the aggregation pheromones have successfully been used for detection and monitoring. ${ }^{10,11}$

For syntheses of abovementioned bisabolenol stink bug pheromones, we earlier explored a rhodium-catalyzed asymmetric addition of trimethylaluminum to diastereomeric mixtures of cyclohex-2-enones. ${ }^{9}$ This conveniently provided two single stereoisomers from one reaction (Scheme 1) and thus allowed us to build a full library of stereoisomers of bisaboladienols and epoxybisabolenols. ${ }^{8,9}$ 

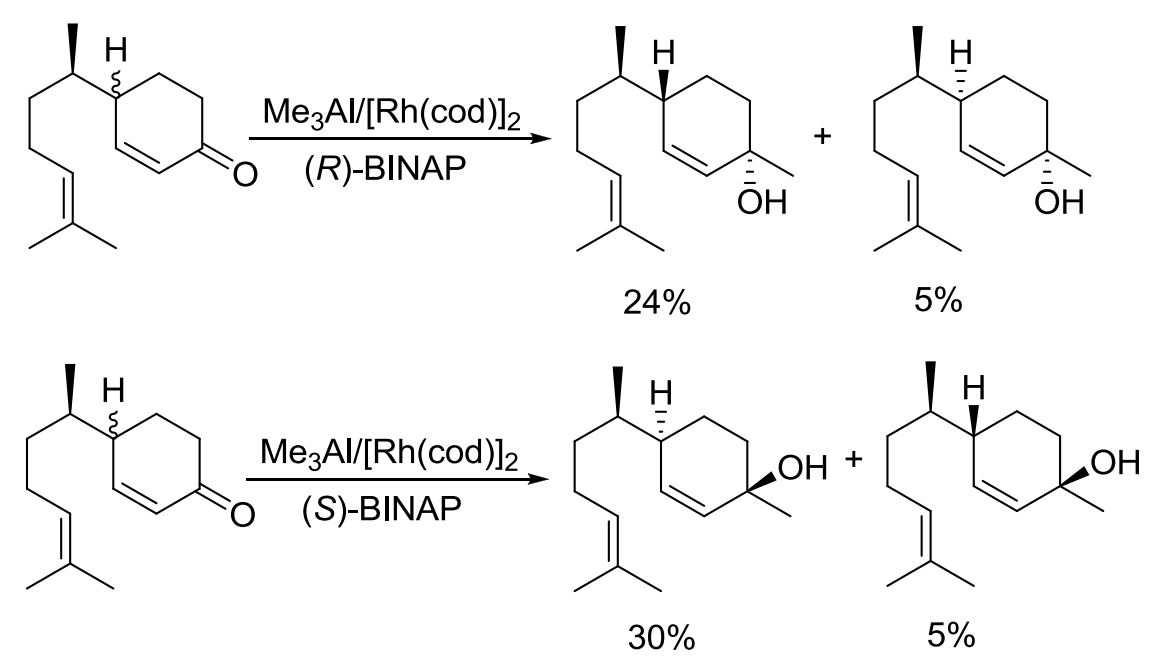

Scheme 1. Previous approach (Ref. 9) to bisabolenol stink bug pheromones

However, the use of expensive catalysts and chiral reagents, and more importantly, low yields of trans isomers, hampered the practical application of this method. To overcome these shortcomings, we contemplated changing our strategy from the Rh-catalyzed enantioselective addition to a carbonyl group to introducing chirality in the precursor cyclohexenone molecule (i.e. ketones $\mathbf{6}$, and 7), then conducting a non-stereoselective addition of methyllithium and capitalizing on easy separation of cis- and trans-1,10-bisaboladien-3-ols. Fortuitously, the stereodefined cyclohex-2-enone 7 has recently been reported in literature, ${ }^{12}$ thus providing an assurance for successfully accomplishing the chosen strategy for the synthesis of bisabolenol stink bug pheromones.

\section{RESULTS AND DISCUSSION}

The catalytic enantioselective Michael addition ${ }^{14}$ of $(S)$-citronellal to methyl vinyl ketone in the presence of $(R)$-diphenylprolinol methyl ether ${ }^{13}$ provided ketoaldehyde 8 in $65 \%$ yield and 95:5 dr (Scheme 2), with the diastereoselectivity in agreement with the originally reported 
addition of $(R)$-citronellal to methyl vinyl ketone catalyzed by $(S)$-diphenylprolinol. ${ }^{12}$ The latter reaction in our hands provided ketoaldehyde 9 in $69 \%$ yield and 96:4 dr.

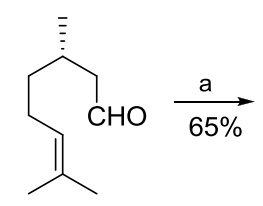

(S)-citronellal

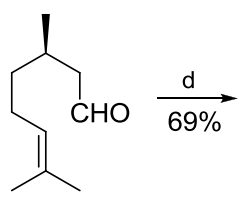

$(R)$-citronellal

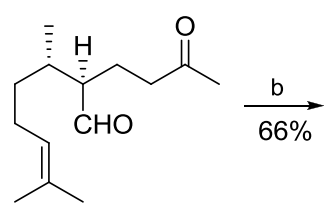

8, $95: 5 \mathrm{dr}$

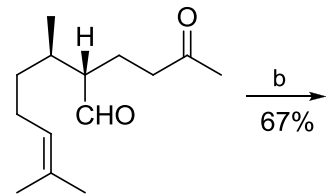

9, $96: 4 \mathrm{dr}$

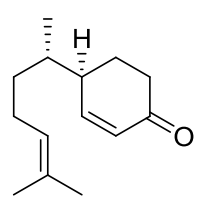

6, $92: 8 d r$

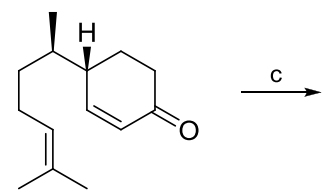

$7,92: 8 d r$

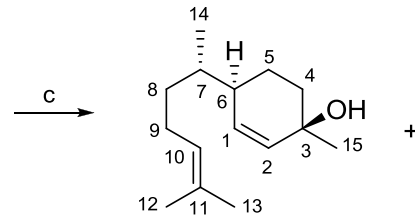

$1(31 \%, 91: 9 \mathrm{dr})$

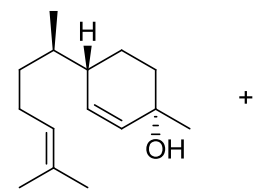

$10(35 \%)$

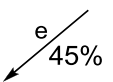

$f \downarrow 60 \%$

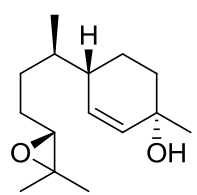

3, $91: 9 d r$

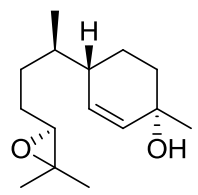

4, $91: 9 d r$

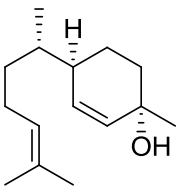

$2(40 \%, 92: 8 \mathrm{dr})$<smiles>CC(C)=CCCC(C)[C@H]1C=CC(C)(O)CC1</smiles>

$11(45 \%)$

$\mathrm{e} \downarrow 36 \%$

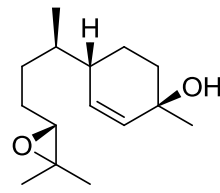

5, $91: 9 d r$

Reagents and conditions: a) $\mathrm{CH}_{3} \mathrm{C}(\mathrm{O}) \mathrm{CH}=\mathrm{CH}_{2} /(R)$-Diphenylprolinol methyl ether, Ref. ${ }^{12}$; b) $10 \%$ LiOH. $\mathrm{H}_{2} \mathrm{O} / i-\mathrm{PrOH}$, rt, c) MeLi/ether, $-22{ }^{\circ} \mathrm{C}$; d) $\mathrm{CH}_{3} \mathrm{C}(\mathrm{O}) \mathrm{CH}=\mathrm{CH}_{2} /(S)$-Diphenylprolynol methyl ether; e)1. AD-mix- $\beta$; $2 . \mathrm{MsCl} / \mathrm{Py}, 3 . \mathrm{KOH} / \mathrm{MeOH}$; f) 1. AD-mix- $\alpha$; 2. MsCl/Pyridine, 3. $\mathrm{KOH} / \mathrm{MeOH}$;

Scheme 2. Syntheses of rice stink bug (1), brown marmorated stink bug $(\mathbf{3}+\mathbf{5})$, and harlequin bug $(\mathbf{3}+\mathbf{4})$ pheromones through stereoisomeric cyclohexenones 6 and 7

The main challenge in the intramolecular aldol condensation of 8 and $\mathbf{9}$ to cyclohexenones 6 and 7, respectively, was the requirement to conduct them without significant epimerization at the stereocenters adjacent to the aldehyde groups. Nicolaou et al. reported a base-catalyzed cyclization of 9 using $\mathrm{KOH} / \mathrm{Bu}_{4} \mathrm{NOH}$ that provided 7 in $85 \%$ yield and 12:1 (92:8) dr. ${ }^{12}$ Somewhat reduced diastereoselectivity ( $83 \%$ de, or 89:11 dr) in the same base-catalyzed 
conversion of 9 to 7 was reported by others. ${ }^{15}$ Despite our concerted efforts, we were unable to reproduce the described diastereoselectivity and isolated cyclohexenone 7 in 82:18 $\mathrm{dr}$. We found that a reflux of the reaction mixture with $\mathrm{KOH} / \mathrm{Bu}_{4} \mathrm{NOH}$ under vigorous stirring for 8 hours as recommended $^{12}$ lead to a significant amount of an intermediate compound visible by TLC (expectedly an aldol product), and the completion of condensation required a prolonged heating $(18-20 \mathrm{~h})$ resulting in $82: 18 \mathrm{dr}$, presumably due to epimerization to $(R, R)$-diastereomer of $7 .^{16}$ In fact, other authors applying the same $\mathrm{KOH} / \mathrm{Bu}_{4} \mathrm{NOH}$ base system for the asymmetric synthesis of a structurally analogous cryptone also reported a loss of enantiopurity from $92-95 \%$ ee (in starting (S)-2-isopropyl-5-oxohexanal) to $56 \%$ ee in final $(S)$-cryptone. ${ }^{17}$ Intrigued by a significant mitigation of the loss of enantiopurity when $\mathrm{KOH} / \mathrm{Bu}_{4} \mathrm{NOH}$ was replaced by $\mathrm{LiOH} / i$ PrOH $(89 \%$ ee , or $94.5: 5.5 S / R),{ }^{17}$ we became interested in using this base system for cyclizations of ketoaldehydes $\mathbf{8}$ and $\mathbf{9}$. Thus, stirring aldehydes $\mathbf{8}$ and $\mathbf{9}$ in an $10 \%$ isopropanol solution of lithium hydroxide hydrate at $25{ }^{\circ} \mathrm{C}$ for $5 \mathrm{~h}$ proceeded without significant epimerization and provided ketones 6 and 7 in 66\% and 67\% yields, respectively, and 92:8 dr (SM=Supplementary Material, p. 6-8). We also found that lithium hydroxide hydrate as a source of $\mathrm{LiOH}$ provided a more reproducible and better stereochemical output than anhydrous lithium hydroxide, and the cyclization is facilitated by an initial ultrasonication.

A non-stereoselective addition of methyllithium to enone $\mathbf{6}$ provided $(3 R, 6 R, 7 S)-1,10$ bisaboladien-3-ols (1) in 31\% yield and 91:9 dr and (3R,6S,7R)-1,10-bisaboladien-3-ols (2) in 40\% yield and 92:8 dr (SM, p. 9-12) easily separated by chromatography on silica. As mentioned in the Introduction, dienol $\mathbf{1}$ is a pheromone of the rice stink bug, Oebalus poecilus, ${ }^{3,4}$ and both dienols $\mathbf{1}$ and $\mathbf{2}$ were also found in ginger. ${ }^{5}$ Analogously to the reaction with $\mathbf{6}$, a nonstereoselective addition of methyllithium to enone 7 provided $(3 S, 6 S, 7 R)$-1,10-bisaboladien-3-ol 
(10) in 35\% yield and $(3 R, 6 S, 7 R)-1,10$-bisaboladien-3-ol (11) in $45 \%$ yield. Thus, both $H$. halys and $M$. histrionica pheromone precursors were synthesized from one reaction in comparable yields, whereas the previous synthesis required two Rh-catalyzed reactions (one with $(R)$-BINAP and the other one with (S)-BINAP) to make 10 and $11 .{ }^{9}$ Most importantly, the yield of the sterically disfavored trans isomer 11 was improved from $5 \%{ }^{9}$ to $45 \%$. Enantioselective epoxidations of bisaboladienols $\mathbf{1 0}$ and $\mathbf{1 1}$ were conducted via earlier described asymmetric dihydroxylations, conversion of intermediate triols to secondary mesylates and further eliminations to epoxides 3-5. ${ }^{9}$ The diastereomeric ratios of epoxides 3-5 were about 91:9 (SM, pp. 13-18), somewhat lower than 95:5 dr reported for these compounds in the previous

communication. ${ }^{9}$ Hence, there was a need to compare the attractiveness of the newly synthesized and the original epoxybisabolenol pheromone samples.

A short field trapping experiment with harlequin bugs showed that numbers of both adult and nymphal bugs attracted to two pheromone treatments, 1.4:1 3/4, of 91:9 and 95:5 dr, were similar (Table 1).

Table 1. Total numbers of harlequin bugs attracted to host plants in three-way choice test, Beltsville, Maryland, 18-24 August 2015.

\begin{tabular}{|c|c|c|}
\hline $\begin{array}{l}\text { Lure } \\
\text { treatment }\end{array}$ & $\underline{\text { Total adults }}^{a}$ & Total nymphs \\
\hline $\begin{array}{l}1.4: 13 / 4, \\
95: 5 \mathrm{dr}\end{array}$ & $120 \mathrm{a}$ & $37 \quad \mathrm{a}$ \\
\hline $\begin{array}{l}\text { 1.4:1 3/4, } \\
91: 9 \mathrm{dr}\end{array}$ & 99 & $35 \mathrm{a}$ \\
\hline Blank & $2 b$ & $0 \mathrm{~b}$ \\
\hline
\end{tabular}


${ }^{a}$ Within the same column, treatments followed by the same letter do not differ $(\mathrm{p}<0.05)$ by exact binomial test. ${ }^{18}$

Overall difference among the three treatments is significant by $\chi^{2}$ goodness-of-fit test ${ }^{18}$ (for adults, $\chi^{2}=107.6, \mathrm{df}=2, \mathrm{p}<0.0001$; for nymphs, $\chi^{2}=36.1, \mathrm{df}=2, \mathrm{p}<0.0001$ ), but these differences were solely due to differences of both pheromone treatments compared to the blank. Thus, pheromones produced by the current method can successfully be used for monitoring stink bug populations.

In conclusion, a new method for the synthesis of bisabolenol stink bug pheromone via cyclohexenones 6 and 7 was developed providing an easy access to both cis- and trans-1,10bisaboladien-3-ols. Because of the availability of both L- and D-prolines, starting compounds to make $(S)$ - and $(R)$-diphenylprolinol methyl ether catalysts, the method is expected to be applicable for syntheses of all stereoisomers of 10,11-epoxy-1-bisabolen-3-ols and 1,10bisaboladien-3-ols.

\section{ACKNOWLEDGMENT}

Support for this study was from USDA, National Institute of Food and Agriculture, Specialty Crop Research Initiative grant \#2011-51181-30937.

\section{SUPPLEMENTARY MATERIAL}


Supplementary information associated with this article including all experimental procedures and ${ }^{1} \mathrm{H}$ NMR spectra can be found in the online version.

\section{REFERENCES:}

1. For terpene nomenclature see: Connolly, J. D.; Hill, R. A. Dictionary of Terpenoids, Chapman and Hall, London, 1991; Vol. 1, pp 180-182.

2. Borges, M.; Birkett, M.; Aldrich, J. R.; Oliver, J. E.; Chiba, M.; Murata, Y.; Laumann, R. A.; Barrigossi, J. A.; Pickett, J. A.; Moraes, M. C. B. J. Chem. Ecol. 2006, 32, 2749.

3. de Oliveira, M. W. M.; Borges, M.; Andrade, C. K. Z.; Laumann, R. A.; Barrigossi, J. A. F.; Blassioli-Moraes, M. C. J. Agric. Food. Chem. 2013, 61, 7777.

4. de Oliveira, M. W. M.; Borges, M.; Andrade, C. K. Z.; Laumann, R. A.; Barrigossi, J. A. F.; Blassioli-Moraes, M. C. J. Agric. Food. Chem. 2014, 62, 8542.

5. Khrimian, A.; Shirali, S.; Guzman, F. J. Nat. Prod. 2015, 78, 3071.

6. Zahn, D. K.; Moreira, J. A.; Millar, J. G. J. Chem. Ecol. 2008, 34, 238.

7. Zahn, D. K.; Moreira, J. A.; Millar, J. G. J. Chem. Ecol. 2012, 38, 126.

8. Khrimian, A.; Shirali, S.; Vermillion, K. E.; Siegler, M. A.; Guzman, F.; Chauhan, K.; Aldrich, J. R.;Weber, D. C. J. Chem. Ecol. 2014, 40, 1260.

9. Khrimian, A.; Zhang A.; Weber, D. C.; Ho, H.-Y.; Aldrich, J. R.; Vermillion, K. E.; Siegler, M. A.; Shirali, S.; Guzman, F.; Leskey, T. C. J. Nat. Prod. 2014, 77, 1708.

10. Leskey, T. C.; Khrimian, A.; Weber, D. C.; Aldrich, J. R.; Short, B. D.; Lee, D.-H.; Morrison, W. R. J. Chem. Ecol. 2015, 41, 418.

11. Weber, D. C.; Cabrera Walsh, G.; DiMeglio, A. S.; Athanas, M. M.; Leskey, T. C.; Khrimian. A. J. Chem. Ecol. 2014, 40, 1251. 
12. Nicolaou, K. C.; Wu, T. R.; Sarlah, D.; Shaw, D. M.; Rowcliffe, E.; Burton, D. R. J. Am. Chem. Soc. 2008, 130, 11114.

13. Enders, D.; Kipphardt, H.; Gerdes, p.; Brena-Valle, L. J.; Bhushan, V. Bull. Soc. Chim. Belg. 1988, 97, 691.

14. Chi, Y.; Gellman, S. H. Org. Lett. 2005, 7, 4253.

15. Yadav, J. S.; Thirupathaiah B.; Srihari P. Tetrahedron, 2010, 66, 2005.

16. Houjeiry, T. I., Poe, S. L., McQuade, D. T. Org. Lett. 2012, 14, 4394.

17. Chen, K.; Ishihara, Y.; Galan, M. M.; Baran, P. S. Tetrahedron, 2010, 66, 4738.

18. Lowry, R. 2017. VassarStats: Website for Statistical Computation. http://vassarstats.net. Accessed 2 March. 
Graphical Abstract

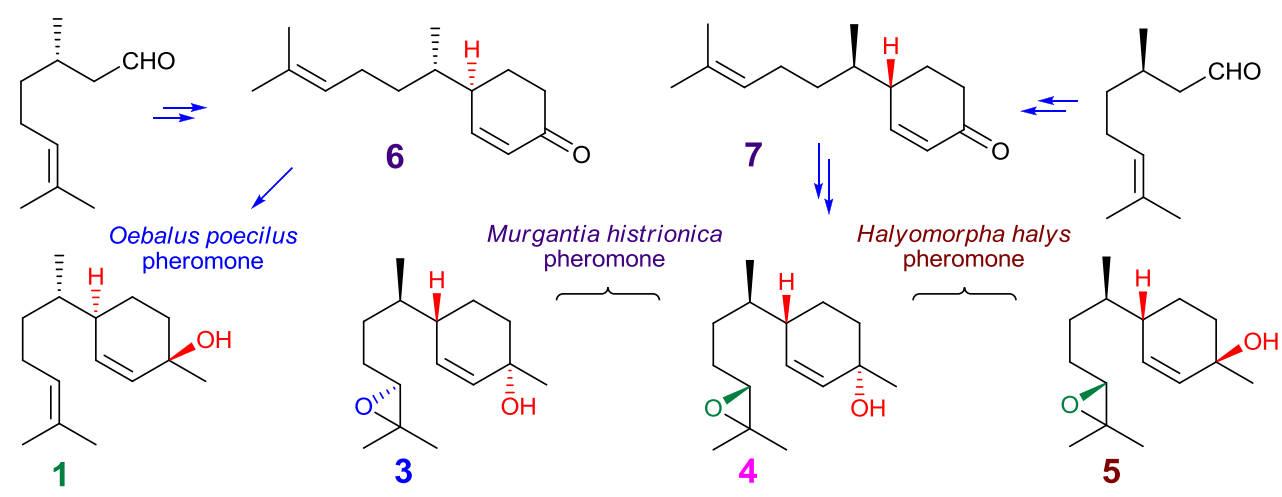

